\title{
New Research on Teaching Path of Sinology Education in Colleges and Universities in the Context of Micro-era
}

\author{
LiWei $^{1, a}$ \\ ${ }^{1}$ College of basic Science, Harbin University of Commerce, Harbin 150028, China \\ awenxueliwei@163.com
}

Keywords: Sinology Education, Teaching Path, Micro-era

\begin{abstract}
With the rapid development of Sinology, it is urgent to explore the new path of Sinology Education. In the micro-era context, using Moto-teach to construct Wisdom Classes of Sinology Education can make Sinology Education "turn knowledge into wisdom", "human nature management", "interaction into common", "teaching with pleasure"; applying we-chat group, we-chat app and we-chat public platform for teaching, which can enhance the effectiveness of Sinology Education; relying on moral classroom, Sinology community, regional resources to carry out practice teaching which can make Sinology truly "alive". We should innovate the methods of Sinology Education, effectively enhance the effectiveness of Sinology Education, enrich the unique charm of Chinese traditional culture, improve the quality of College students, and enhance the self-confidence of Chinese culture.
\end{abstract}

With the emergence and wide application of WeChat and Weibo, human beings have entered the micro-era. As the first of the pre-Qin Confucian scriptures, "Zhou Yi" emphasizes "time news" and "time with time", and then "advance with the times", in order to "come with the heavens and the earth, match the sun and the moon, and order with the four seasons "[1] Thus, various achievements of great benefit to society should be achieved, and so should the sinology education in colleges and universities.

Faced with the combination of mobile communication technology and Internet, and the rapid upgrading of information modernization, the inheritance and innovation of sinology education in colleges and universities are facing new opportunities and challenges. The seamless connection between the new media and the teaching of Chinese culture is beneficial to the reform and development of the sinology education in colleges and universities, and to the improvement of the effectiveness of the sinology education.

\section{Using Mosoteach to construct sinology wisdom classes}

Constructing the sinology wisdom classes is inseparable from the application software of mobile internet and cloud technology, but mosoteach can meet this demand. Mosoteach is based on network environment and cloud service, using mobile smart devices (mainly computer and mobile phone) to organize teaching, realizing instant interaction, feedback and evaluation inside and outside the classroom, helping teachers to effectively carry out micro-classroom, JiTT teaching and A client app that flips classrooms and other teaching modes, and has functions such as intelligent evaluation of teaching evaluation.[2] The following four aspects are used to explore the great help of the Mosoteach to construct sinology wisdom classes.

1.1 "Transfer knowledge into wisdom", Mototeach is a new platform for constructing sinology wisdom classes in colleges and universities

The so-called "turning knowledge into wisdom" is interpreted by Feng Qi as "turning theory into method" in epistemology and "turning theory into virtue" in axiology. Compared with the traditional classes, the wisdom classes pays more attention to the cultivation of competence and quality, and pays more attention to transforming the external knowledge into the educational effectiveness of internal cultivation, and pays more attention to "transforming knowledge into wisdom". 
The "Resources" module of Mototeach can upload relevant sinology materials (audio, video, web links, etc.) to create good conditions for the class to "transfer knowledge into wisdom", extend the class beyond the class, and extend to student life. The "Homework/Group Tasks" and "Discussion/Q\&A" modules of Mototeach can promptly carry out multi-interactive knowledge internalization, and teachers can clearly understand the basic situation of each student's "transfer knowledge into wisdom". And based on this, make appropriate adjustments in content and methods.

1.2 "Humanity Management", Mototeach is a new helper for constructing sinology wisdom classes in colleges and universities.

The wisdom classes in the classes management beyond the traditional classes "in order to achieve the final grade or pass or not" this simple rough or "master lead in the door, practice in everyone" sheep-herding management model, implementing "human nature management". The so-called "humanity management" does not refer to the humanized education and teaching management, but refers to the education and teaching management that conforms to the human heart and conforms to the basic situation of human nature. The method used is not administrative, but rather psychological. That is to say, when organizing teaching and managing classrooms, it focuses on the use of "sparse" methods, rather than promoting the use of "blocking" methods. [3] Mototeach completely subverts the way traditional classes treat students' mobile phones in the teaching of sinology education, and requires students to bring mobile phones into the class. This not only satisfies the psychology of students playing mobile phones, but also can turn the mobile phone into a good tool for students to learn in a dredging manner, which can well resolve the embarrassing situation of mobile phones and teachers competing for students. Mototeach also has a "questionnaire" function, which can effectively conduct all kinds of questionnaires in real time, and find the psychological will of most students in the shortest time.

1.3 "Interaction is common", Mototeach is a new tool for constructing sinology wisdom classes in colleges and universities.

The interaction of traditional classes can only take one-to-one (teachers and some students) face-to-face. It is difficult to achieve full participation of students. If students are divided into groups to conduct group interaction and group interaction, they can achieve full participants participate, but in the same classroom, between groups and groups will inevitably interfere with each other, which will weaken the interaction effect. The "Discussion/Q\&A" functions of Mototeach can realize the full open interactive communication within the online time-specific class. This form will not form a situation that interferes with each other, but will also guide and motivate those who are inferior to participate in discussions and exchanges to a large extent, thereby enhancing the level of interaction. At the same time, Mototeach also has a "brainstorming" function, which is a semi-open interactive discussion forum inside the online time-specific class. In the "brainstorming", the teacher asks questions and the students can't see each other when answering. The other party's point of view and answer can only be seen after the teacher finishes the activity. This form can also bring students a sense of potential expectation while attracting students to participate in interactive communication, thus enhancing the quality and effectiveness of interactive communication. Whether it is a full-open interactive communication or a semi-open interactive communication, teachers can firmly control students by adopting plus or minus experience values, thus ensuring the effective development of interactive communication.

1.4 "Education in fun", Mototeach is a new means for constructing sinology wisdom classes in colleges and universities.

In the micro-era, the wisdom classes of sinology education in colleges and universities should not be as serious and formal as the traditional classes; otherwise it will lose the market of knowledge dissemination and quality training. If you can't really "Education in fun", it is very difficult to receive good education and teaching effects. Mototeach itself is teaching help software that has many functions of "Education in fun". The application of Mototeach in teaching can well bring students into "happiness" and carry out "teaching". For example, In the classes questioning session, teachers can use the "shake and shake" function to randomly name, enhance the fun and mystery of the classes, and effectively focus students' attention and motivate students. [4] 


\section{Enhance the cultural effectiveness of sinology education based on WeChat platform.}

2.1 Enhance the effectiveness of sinology education by using WeChat group teaching.

We use WeChat teaching in sinology classes to strengthen communication and communication between teachers and students, and effectively enhance the effectiveness of Chinese education in universities, mainly in the following aspects:

First, the WeChat group has become a resource sharing platform between teachers and students. Teachers and students, especially teachers, can share the resources of sinology in the WeChat group anytime and anywhere, laying the foundation for the in-depth development of sinology education and the internalization of content. Second, the one-dimensional teaching model is a multi-interactive teaching model. The traditional teaching mode is often "one-say", the teacher-student interaction is often one-to-many, and even the group discussion is subject to the number of speakers. Through WeChat teachers and students can conduct full discussion and communication, stimulate students' initiative and enthusiasm, and teachers understand student dynamics. Third, breaking the boundaries of time and space, making Chinese education all the time, everywhere. The traditional classes are immediacy. The end of the class means the end of teaching. With WeChat, you can break the time and space restrictions. Students can ask questions at any time. Teachers answer questions at any time. Teachers and students can interact and communicate at any time and place.

2.2 Increase the vitality of sinology education by developing WeChat applet.

Colleges and universities can make full use of the WeChat platform to achieve "micro-ization" of sinology education. Design a simple WeChat applet or mobile game, embedding sinology learning content, such as the "Second Change Poetry" small program is to embed the content of poetry into small programs. The poetry into the public life, college students enhance their love for poetry in the "play" process, and enhance the desire to create poetry independently, and improve the cultivation of poetry. Another example is to carry out the sinology knowledge contest on the WeChat platform, set up a small program to attract more college students to actively learn the sinology culture, and improve the awareness of sinology culture and improve the quality of sinology studies.

2.3 Enhance the publicity and education of sinology culture by using the WeChat public platform.

Make full use of the school's influential WeChat public platform to facilitate students to acquire, disseminate, push, and evaluate the sinology culture, open up students' horizons, and promote the education of sinology culture. On the one hand, through the network live broadcast, MV, H5, singing, performance, recitation, narrative and other college students like to push the relevant content of sinology culture, attract more students to use the fragmented time to study sinology e classics. On the other hand, establish a public platform for Sinology education independently, through holding poetry contest, Chinese learning knowledge contest and prize-winning essay collection activities, online and offline interaction is formed, highlighting the value and role of the micro-era, stimulating the enthusiasm of college students' and improving the learning effect. Set up interactive columns, set relevant sinology-speaking exchange topics regularly, attracting students to share learning experiences, or publish their own classics, apply the knowledge that students have learned in the classes to practice, and enhancing the effectiveness of sinology education.

\section{Pay attention to practical teaching and let sinology learning "live".}

3.1 Relying on the moral classroom, let sinology take root and sprout.

Make full use of the moral classroom, carry out a series of ethical culture training activities, and savor the sinology classics and brew the fragrance of morality together. By singing a classic song, watching a classic short film, reading a classic essay, telling a classic story, making a classic review, starting from the nuances, making college students feel that morality is everywhere, internalizing traditional culture into the mind and externalize it. It plays its due role in promoting the excellent traditional culture of China, enhancing the cultural quality of college students, and building a harmonious cultural campus.

3.2 Relying on sinology societies, let national studies blossom everywhere. 
Relying on the Chinese Learning Societies in schools such as the Chinese Writing Poetry Association, the Calligraphy Association, the Checkerboard Association, the Hanfu Society, the Wushu Association and the Drama Society, we have carried out a series of cultural experience activities, such as Chinese learning forums, classical Chinese reading, poetry competitions, symposiums, lectures by famous masters and masters, to experience the broad and profound Chinese culture. At the same time, the carrier of innovative activities, the integration of the first classes of sinology studies, with the help of campus new media dissemination, to create a cultural atmosphere of sinology studies to innovate the content and form of the activities of the sinology society brand, so that college students to participate in the experience of the beauty of classical poetry, the charm of ancient music, the spirit of Chinese tea, taste the unique charm of Chinese culture. In addition, the sinology studies association should also go out of the campus, to the community, to the brothers'colleges, social enterprises to perform, to learn and exchange experience, so that more people approach sinology studies, innovative and open thinking to carry forward the practice of Chinese traditional culture.

3.3 Relying on regional resources, let sinology be at hand. [5]

Give full play to regional and resource advantages, rely on the provinces where the universities are located in the ruins, cultural scenic spots, folk customs, literary and creative works, regular visits and research, accept the edification of traditional culture, feel the unique charm of traditional culture. At the same time, study the regional culture, to explore the root and context of regional culture, enhance the local cultural heritage, so that Chinese culture can be felt everywhere, within reach.

\section{Conclusion}

With the rapid development of sinology, sinology education tends to be weakened or marginalized. It is very important to study the reform of teaching methods of sinology education in Colleges and universities so as to enhance the actual effect of sinology education. In the micro-era context, along with the rapid development of Internet, multimedia and mobile terminal technology, introducing the form of Mototeac, Weixin, practical teaching into sinology education, carrying out corresponding teaching and practical activities, can effectively improve the teaching effect of sinology education. Introducing the latest scientific and technological achievements of the micro-era into the sinology Classes will be of great significance to the traditional classes to improve the teaching methods and enhance the teaching effect.

\section{References}

[1] Huang Shouqi, Zhang Shanwen. Zhouyi translation annotation[M]. Shanghai ancient book publishing house.2004, p29.

[2] Qi Aiping. Application of Mototeach in Teaching [J].Information and Computer, 2016 (19).

[3] Zhang Zhongguang, Li Wei, Cui Li, Liu Li, Zhang Haitong. Research on the "three-person" teaching mode of Ideological and political course in Colleges and Universities under the concept of college education [J].Learning Theory, 2016 (10).

[4] Meng Tingting. Some thoughts on the application of Mototeach in the teaching process [J]. Vocational education, 2016 (05).

[5] Liu feng, Yang ying. Research on the teaching content and mode innovation of Chinese studies in higher education [J]. Journal of Inner Mongolia agricultural university (social science edition),2018(2). 